Pengaruh Latihan Ballhandling ....(Rury Rizhardi)

\title{
PENGARUH LATIHAN BALLHANDLING TERHADAP HASIL DRIBBLING BOLA BASKET PADA SISWA EKSRAKURIKULER SMAYADIKA LUBUK LINGGAU
}

\author{
Oleh: Rury Rizhardi \\ (Dosen Universitas PGRI Palembang) \\ Email: $\underline{\text { rury_rizhardi@yahoo.com }}$
}

\begin{abstract}
Abstrak
Penelitian ini bertujuan untuk mengetahui bahwa adakah pengaruh latihan ball handling terhadap hasil dribbling bola basket pada siswa ekstrakurikuler di SMA YADIKA Lubuk Linggau. Dalam penelitian ini metode yang digunakan adalah metode eksperimen yaitu statistik untuk menentukan pengaruh latihanball handling. Teknik pengumpulan data yang digunakan yaitu dengan tes. Tes dribbling untuk mengukur keterampilan dribbling bola basket. Populasi dalam penelitian ini adalah siswa yang mengikuti kegiatan ekstrakulikuler di SMA YADIKA Lubuk Linggau, yang berjumlah 15 siswa. Data yang diperoleh dianalisis menggunakan rumus statistik uji-t. Hasil analisis dapat dinyatakan ada pengaruh yang kuat antara latihan ball handling terhadap hasil dribbling dalam permainan bola basket pada siswa ekstrakurikuler SMA YADIKA Lubuk Linggau, dapat dilihat dengan hipotesis menggunakan uji $t$ diperoleh $t_{\text {hitung }}$ sebesar 6 dan harga $t_{\text {tabel }}$ sebesar 1,76. Jadi $t_{\text {hitung }}>t_{\text {tabel }}$, dengan demikian $H_{a}$ diterima dan $H_{o}$ ditolak yang artinya terdapat pengaruh yang signifikan latihan ball handling terhadap hasil dribbling bola basket di SMA YADIKA Lubuk Linggau.
\end{abstract}

Kata Kunci: Pengaruh Latihan, Ball Handling, Dribbling Bola Basket.

\begin{abstract}
This study aims to determine whether there is an effect of ball handling training on the results of basketball dribbling on extracurricular students at YADIKA High School Lubuk Linggau. In this study the method used is an experimental method that is statistics to determine the effect of ball handling practice. Data collection techniques used are tests. Dribbling test to measure basketball dribbling skills. The population in this study were students who participated in extracurricular activities at YADIKA Lubuk Linggau High School, The data obtained were analyzed using the t-test statistical formula. Experimental analysis results a strong influence between ball handling training on the results of dribbling in the basketball game on extracurricular students at YADIKA Lubuk Linggau High School, that it can be seen with the hypothesis using the t test obtained by $t_{\text {hitung }}$ of 6 and the $t_{\text {table }}$ price of 1.76. So $t_{\text {hitung }}>t_{\text {tabel }}$, thus $H_{a}$ is accepted and $H_{o}$ is rejected which means there is a significant influence on ball handling training on the results of basketball dribbling at Lubuk Linggau YADIKA High School.
\end{abstract}

Keywords: Exercise Effect, Ball Handling, Basketball Dribbling. 


\section{A. PENDAHULUAN}

Olahraga telah menjadi kebutuhan bagi masyarakat untuk menjaga serta meningkatkan kondisi fisik tubuh agar tetap bersemangat dalam melakukan kegiatan sehari-hari serta berkemampuan untuk berprestasi dengan baik. Hal ini sesuai dengan tujuan khusus dari aktifitas berolahraga, kegiatan olahraga di Indonesia tidak hanya sekedar untuk kesegaran jasmani atau rekreasi saja.

Namun harus berfikir kearah peningkatan prestasi untuk dapat mengharumkan nama bangsa dan negara digelanggang nasional ataupun internasional. Potensi-potensi yang mereka miliki tersebut harus dikembangkan agar tidak menjadi potensi yang terpendam dan sia-sia. Menurut Undang-Undang Republik Indonesia Nomor 3 Tahun 2005 Tentang Sistem Keolahragaan Nasional Pasal 25 ayat 1 berbunyi: "Pembinaan dan pengembangan olahraga pendidikan dilaksanakan dan diarahkan sebagai satu kesatuan yang sistematis dan berkesinambungan dengan sistem pendidikan nasional”.

Pembangunan di bidang olahraga sangat mendapat perhatian dari pemerintah dan masyarakat untuk meningkatkan kesehatan dan kesegaran jasmani bangsa Indonesia. Hal ini dilakukan bukan hanya oleh pemerintah saja, tetapi juga perlu didukung oleh berbagai pihak. Untuk tercapainya masyarakat yang gemar berolahraga diperlukan adanya olahraga berupa permainan yang digemari masyarakat, salah satunya adalah cabang olahraga permainan, seperti permainan bola basket. Permainan atau olahraga bola basket berasal dari luar Indonesia tepatnya di Negara Amerika Serikat. Olahraga ini dari tahun ke tahun semakin berkembang di Negara Afrika Selatan, Eropa Selatan, Lithuania, dan juga di Indonesia.

Permainan bola basket merupakan permainan yang dinamis dan atraktif terutama berkenaan dengan cara memainkan bola baik saat dribble, passing, layup maupun shooting. Beberapa teknik tersebut harus dikuasai oleh pemain basket karena dalam pertandingan bola basket, teknik inilah yang akan menunjang untuk mendapatkan kemenangan. Permainan bola basket semakin menarik ketika para 
Pengaruh Latihan Ballhandling ....(Rury Rizhardi)

pemain memperagakan teknik dribble dengan berbagai atraksi pada saat permainan berlangsung.

Tujuan dari permainan bola basket adalah memasukkan bola ke keranjang lawan dengan sebanyak-banyaknya dan menjaga lawan untuk memperoleh angka. untuk memudahkan memasukan bola diperlukan dribble yang baik. Berdasarkan kondisi pemain bola basket di Indonesia yang berada dalam keterbatasannya, permainan bola basket yang ditampilkan pun ternyata cukup menarik karena para pemain pun dapat menampilkan kemampuan individu, kerja sama tim dan tentunya dapat melakukan dribble dengan baik. Pada pertandingan bola basket sering terlihat kecenderungan-kecenderungan penggunaan berbagai teknik dribble.

Sebelum mempelajari teknik-teknik dasar permainan bola basket yang baik yang akan berpengaruh pada permainan, sangat dibutuhkan teknik dasar penguasaan bola seperti tekni ball handdling yang umum digunakan pemain pada saat pertandingan bola basket. Ball handdling merupakan kemampuan seorang pemain untuk menguasai bola dengan nyaman dalam suatu latihan yang akan menentukan seberapa baik teknik passing, catching, dribbling, dan shooting dari seorang pemain. Kosasih, (2008:18). Setelah seorang pemain dapat menjiwai olahraga tersebut dengan keahlian penguasaan bola juga dibutuhkan penguasaan teknik bermain yang baik, karena kemampuan teknik dalam bermain sangat mendukung dalam meningkatkan keterampilan.

Di antara keterampilan dalam permainan bola basket, kemampuan dribble, passing, dan shooting juga merupakan hal penting dalam mengembangkan seorang pemain basket. Ini merupakan keterampilan dasar yang harus dikembangkan dan dimiliki oleh pemain serta diberikan dalam situasi latihan. Dengan adanya pendapat diatas maka dapat disimpulkan bahwa latihan ball handdling sangat berguna untuk mendukung siswa dalam menguasai teknikteknik dasar bola basket dalam melatih kemampuan dribble, pasing, dan shooting dalam bermain. Karena dribble, passing, dan shooting merupakan teknik dasar bermain bola basket. 
Dari kegiatan ekstrakurikuler bola basket di SMA YADIKA Lubuk Linggau, dengan waktu yang sudah maksimal dalam latihan bola basket pada kegiatan ekstrakurikuler, prestasi yang didapat sampai saat ini kenyataannya masih sangat kurang. Berdasarkan observasi peneliti yang terjadi dilapangan serta dikuatkan dengan pengamatan pada siswa ditemukan adanya masalah yaitu: rendahnya kemampuan dribble pada siswa diduga kurang tepatnya latihan yang diberikan pada setiap kali latihan. Hal ini disebabkan karena pelatih salah dalam memberikan metode latihan, maka dari itu peneliti berusaha meningkatkan kemampuan dribbling melalui latihan ball handdling.

Berdasarkan pemaparan di atas, maka peneliti tertarik untuk meneliti tentang Pengaruh Latihan Ball Handdling Terhadap Hasil Dribbling Bola Basket Pada Siswa Eksrakurikuler SMA Yadika Lubuk Linggau.

\section{B. METODOLOGI PENELITIAN}

Metode penelitian adalah metode yang menjelaskan tentang metode apa yang digunakan dalam penelitian yang digunakan dalam penelitian ini adalah “One Group Pre test Post test Desain” Suryabrata, (2003:101). Dalam rancangan ini digunakan satu kelompok subjek. Pertama-tama dilakukan pengukuran, lalu dikenakan perlakuan untuk jangka waktu tertentu, kemudian dilakukan pengukuran untuk kedua kalinya. Data dikumpulkan berdasarkan dari hasil tes dribble bola basket. Menurut Arikunto (2006:127) mengemukakan, tes adalah semua pertanyaan atau latihan serta alat lain yang digunakan untuk mengukur keterampilan, pengetahuan intelegensi, kemampuan atau bakat yang dimiliki oleh individu atau kelompok. Tes yang digunakan dalam penelitian ini berupa tes dribble permainan bola basket.

Instrument penelitian merupakan tes yang bersifat mengukur, karena berisi tentang pertanyaan atau pernyataan yang alternatif jawabannya memiliki standard jawaban tertentu, benar ataupun salah. Menurut Sugiyono $(2009 ; 76)$ instrumen penelitian adalah suatu alat yang digunakan untuk mengukur fenomena alam maupun sosial yang diamati. Berdasarkan penelitian yang dituliskan peneliti disini 
Pengaruh Latihan Ballhandling ....(Rury Rizhardi)

berarti instrumen penelitian merupakan tes yang digunakan untuk mengukur proses penampilan seseorang dalam melakukan suatu pekerjaan atau pebuatan.

Untuk mengumpulkan data dalam suatu penelitian, kita dapat pula menggunakan instrumen yang telah tersedia dan dapat pula menggunakan instrumen yang dibuat sendiri. Instrumen yang telah tersedia pada umumnya adalah instrumen yang sudah dianggap baku untuk mengumpulkan data variabelvariabel tertentu. Oleh karena instrumen yang digunakan dalam penelitian ini sudah dianggap baku, maka tidak pelu lagi dilakukan uji validitas dan reliabilitas lagi dikarnakan instrumen dalam penelitian ini telah diuji cobakan oleh para ahli, dan yang terlebih penting agar dapat memper hemat waktu dan biaya dalam penelitihan ini, maka peneliti dalam penelitian ini dianggap tidak pelu lagi menguji cobakan instrumen lagi.

Untuk mengetahui data instrument penelitian, peneliti mengadakan pre-test langsung kepada testee dan kemudian diberikan treatment dengan latihan ball handdling serta tes hasil dribbling bola basket.. Metode analisis data merupakan suatu cara yang ditempuh guna memperoleh atau menganalisis data-data yang diperoleh. Analisis tersebut bertujuan untuk kebenaran hipotesis yang telah dirumuskan. Suatu hipotesis akan diterima atau ditolak tergantung dari hasil data. Dalam penelitian ini peneliti menggunakan teknik data statistik dengan metode pre-test dan post-test (tes awal dan tes akhir).

\section{HASIL PENELITIAN DAN PEMBAHASAN}

\section{Hasil Data Pretest}

Sebelum diberi perlakuan (treatment) berupa latihan ball handdling, siswa terlebih dahulu melakukan tes awal (pre-test) dengan melakukan dribling selama 30 detik dan hasil diambil dari banyaknya sampel melewati batas (kun) sebanyak enam buah. diagram batang untuk tes awal (pre-test) adalah sebagai berikut : 
Wahana Didaktika Vol. 18 No.1 Januari 2020 : 7-14

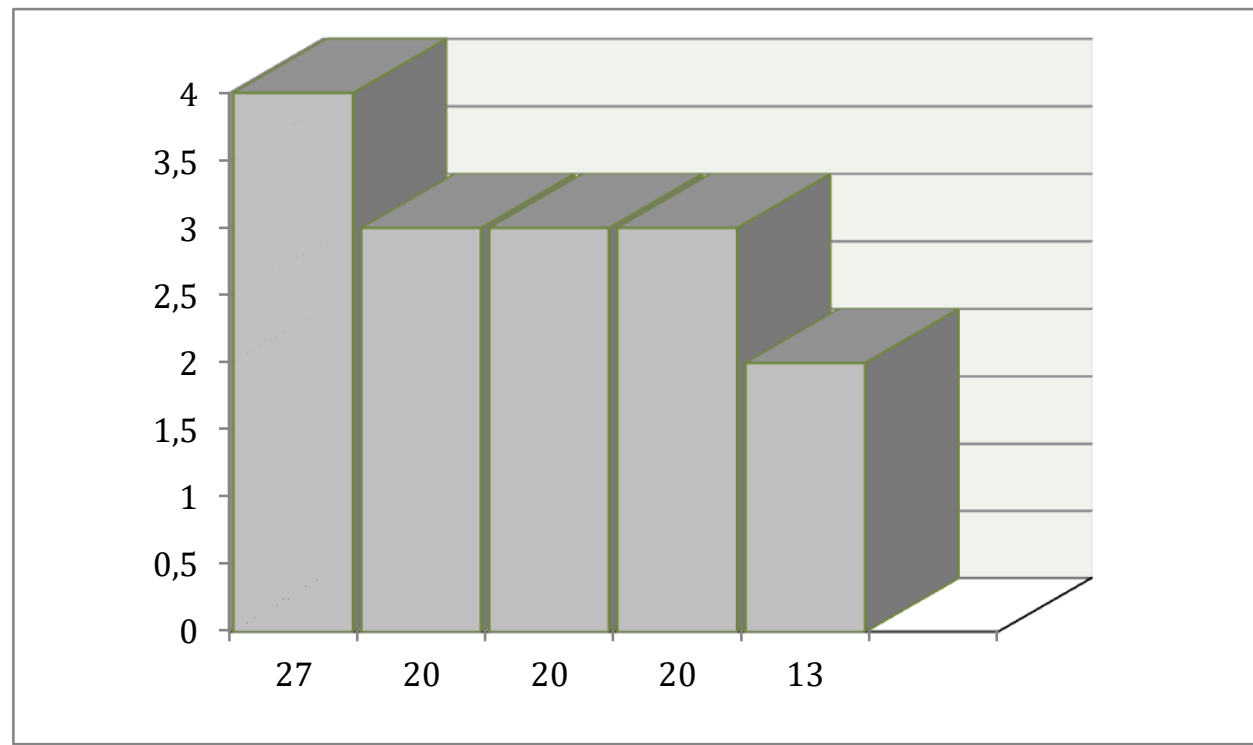

Gambar 1. Histogram Tes Awal

\section{Hasil Data Posttest}

Setelah siswa melakukan tes awal (pre-test) dan diberi perlakuan (treatment) berupa latihan ball handdling, selanjutnya siswa melakukan tes akhir (post-test) yaitu melakukan dribbling selama 30 detik dan hasil diambil dari banyaknya sampel melewati batas (kun) sebanyak enam buah.

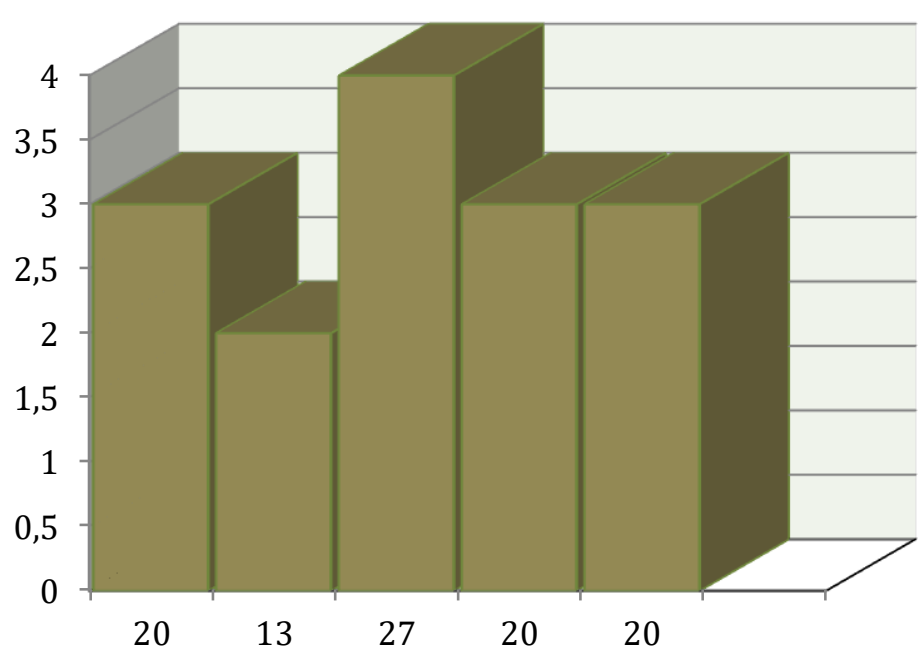

Gambar 2. Histogram Tes Akhir 
Pengaruh Latihan Ballhandling ....(Rury Rizhardi)

Jadi, besarnya pengaruh metode latihan ball handdling terhadap hasil dribbling permainan bola basket peserta ekstrakurikuler SMA YADIKA Lubuk Linggau adalah $29,16 \%$, sedangkan $70,84 \%$ dipengaruhi oleh faktor lainnya seperti postur tubuh yang ideal, kemampuan teknik dasar yang sudah dikuasai, dan motifasi dalam diri.

\section{PEMBAHASAN}

Berdasarkan hasil penelitian yang dilaksanakan, maka penulis dapat menyimpulkan bahwa terdapat pengaruh yang signifikan latihan Ball Handdling terhadap hasil dribbling di SMAYADIKA Lubuk Linggau. Hal tersebut dapat dilihat dari hasil dribbling yang diperoleh dari tes akhir (post-test) lebih besar dari hasil dribbling pada saat tes awal (pre-test). Kenyataan ini dapat dilihat dari masing-masing nilai rata-rata tes. Untuk nilai rata-rata tes awal (pre-test) yaitu 9,53 dengan standar deviasi13,89 sedangkan untuk nilai rata-rata tes akhir (posttest) yaitu 12,53 dengan standar deviasi 19,67.

Selanjutnya untuk melihat atau mengetahui seberapa besar pengaruh latihan ball handdling terhadap hasil dribbling siswa dilakukan uji signifikan dan diperoleh nilai harga $t_{\text {hitung }}$ sebesar 6 dan harga $t_{\text {tabel }}$ sebesar 1,76. Jadi $t_{\text {hitung }} 6>$ $t_{\text {tabel }}$ 1,76. Dengan demikian $\mathrm{H}_{\mathrm{a}}$ diterima dan $\mathrm{H}_{\mathrm{o}}$ ditolak yang artinya terdapat pengaruh yang signifikan latihan ball handdling terhadap hasil dribbling bola basket di SMA YADIKA Lubuk Linggau.

Dalam kajian fisiologi olahraga menjelaskan bahwa latihan akan menyebabkan terjadinya perubahan-perubahan anatomis, kimiawi, danfisiologis. latihan yang berasal dari kata training adalah suatu proses penyempurnaan kemampuan berolahraga yang berisikan materi, teori dan praktik, menggunakan metode dan aturan pelaksanaan dengan pendekatan ilmiah, memakai prinsipprinsip latihan yang terencana dan teratur, sehingga tujuan latihan dapat tercapai tepat pada waktunya. 
Seperti Menggiring atau dribbling bola adalah salah satu dasar bola basket yang pertama diperkenalkan kepada para pemula, karena keterampilan ini sangat penting bagi setiap pemain yang terlibat dalam pertandingan bola basket (Oliver, 2008:49). Dengan demikian maka dapat dijelaskan pentingnya latihan ball handdling yang baik sehingga dapat meningkatkan kemampuan dribbling bola basket, kemudian latihan ball handdling juga memiliki peran dalam kemampuan dribbling, artinya semakin meningkat kemampuan ball handdling maka semakin baik kemampuan dribbling. Hal tersebut juga dijelaskan pada hasil perlakuan yang diberikan yang mana metode latihan ball handdling dapat meningkatkan hasil kemampuan dribbling.

\section{SIMPULAN}

Rata-rata tes awal (pre-test) yang didapat dari hasil dribbling peserta dalam permainan bola basket adalah 9,53 dengan standar deviasi 13,89. Sedangkan ratarata tes akhir (post-test) yang didapat dari hasil dribbling peserta dalam permainan bola basket adalah 12,53 dengan standar deviasi 19,67.

Untuk mengatahui besaran pengaruh latihan ball handdling terhadap hasil dribbling, selanjutnya dilakukan uji signifikan dan didapatkan harga $t_{\text {hitung }}=6$ sedangkan $t_{\text {tabel }}=1,76$. Hal ini menunjukkan bahwa ada pengaruh yang latihan ball handdling terhadap hasil dribbling atas di SMA YADIKA Lubuk Linggau.

\section{DAFTAR PUSTAKA}

Undang-undang RI No 3 Tahun 2005 Tentang Sistem Keolahragaan Nasional. Kementrian.Negara Pemuda dan Olahraga Republik Indonesia

Arikunto, Suharsimi. (2010). Prosedur Penelitian. Jakarta: Rineka Cipta.

Kosasih, Danny. (2008). Fundamental Basketball. Semarang: Karangturi Media.

Oliver, Jon. (2008). Dasar-Dasar Bola Basket. Bandung: Pakar Raya.

Sugiyono. (2009). Metode Penelitian Kuantitatif Kualitatif dan $R \& D$. Bandung:Penerbit Alfabeta

Suryabrata, Sumardi. (2003). Metode Penelitian. Jakarta : Raja Grafindo Persada. 